\title{
CONCEITOS, ARGUMENTOS, ESTRATÉGIAS, MÉTODOS, TÉCNICAS E PROBLEMÁTICAS ENVOLVENDO A IMPLANTAÇ̃̃̃O DA SINALIZAÇÃO DE ORIENTAÇÃO TURÍSTICA EM SÍTIOS HISTÓRICOS.
}

\author{
CONCEPTS, ARGUMENTS, STRATEGIES, METHODS, TECHNIQUES AND \\ PROBLEMS INVOLVING THE IMPLANTATION OF TOURISM ORIENTATION \\ SIGNALING IN HISTORICAL SITES.
}

\section{CONCEPTOS, ARGUMENTOS, ESTRATEGIAS, MÉTODOS, TÉCNICAS Y PROBLEMÁTICAS ENVOLVENDO LA IMPLANTACIÓN DE LA SEÑALIZACIÓN DE ORIENTACIÓN TURÍSTICA EN SITIOS HISTÓRICOS.}

\begin{abstract}
Ana Paula Rodrigues ${ }^{1}$ Emanoel Silva De Amorim ${ }^{2}$

\section{RESUMO}

Esta pesquisa trabalha com a imagem das cidades históricas, mais especificamente, tratou-se de apresentar uma revisão bibliográfica sobre os conceitos e argumentos ligados a implantação da sinalização de orientação turísticas em sítios históricos. Apresentando estratégias e métodos com bases em estudos de caso realizados nos projetos de sinalização de orientação turística na ${ }^{1}$ Cidade de Olinda (Pernambuco), na ${ }^{2}$ Cidade do Recife (Pernambuco), nos ${ }^{3}$ Polos Turísticos Serrano e Agreste/Trairi (Rio Grande do Norte). Além de citar as técnicas e as problemáticas que envolve a implantação deste tipo de infraestruturas em locais históricos tombados pelo IPHAN. O objetivo do trabalho é demonstrar a importância do conhecimento, embasando e justificando através de argumentos a necessidade do investimento nessa tipologia de infraestrutura, além da sua acuidade no processo de preservação dos bens culturais. Por fim, conclui-se que a eficiência desta infraestrutura urbana pode contribuir também para o aumento da permanência do turista no local, e do gasto médio durante sua estadia.
\end{abstract}

Palavras-chave: Mobilidade Urbana; Patrimônio Histórico; Sinalização Turística; Infraestrutura Urbana.

\begin{abstract}
This research works with the image of the historical cities, more specifically, it was to present a bibliographical revision on the concepts and arguments related to the implantation of the signage of tourist orientation in historical sites. Presenting strategies and methods based on case studies carried out in tourist signaling projects in ${ }^{1} \mathrm{City}$ of Olinda (Pernambuco), in the city of Recife (Pernambuco), in the ${ }^{3}$ Tourist Poles Serrano and Agreste / Trairi (Rio Grande do Norte). In addition to mentioning the techniques and problems involved in the implementation of this type of infrastructure in historic sites listed by IPHAN. The objective of this work is to demonstrate the importance of knowledge, supporting and justifying through arguments the need for investment in this typology of infrastructure, as well as its accuracy in the process of preserving cultural assets. Finally, it is concluded that the efficiency of this urban infrastructure can also contribute to the increase of the stay of the tourist in the place, and of the average expense during its stay.
\end{abstract}

Key words: Urban mobility; Historical Patrimony; Tourist Signage; Urban infrastructure.

\section{RESUMEN}

Esta investigación trabaja con la imagen de las ciudades históricas, más específicamente, se trató de presentar una revisión bibliográfica sobre los conceptos y argumentos ligados a la implantación de la señalización de orientación turística en sitios históricos. En el marco de los estudios de caso realizados en los proyectos de señalización de orientación turística en la ${ }^{1}$ Cidad de Olinda (Pernambuco), en la ${ }^{2}$ Cidad de Recife (Pernambuco), en los ${ }^{3}$ Polos

\footnotetext{
${ }^{1}$ Doutora em Educação (2012) pela Universidade de La Empresa (UDE/Uruguai) - Diploma Reconvalidado (2017) pela Universidade Federal de Uberlândia. Mestre em Meio Ambiente e Sustentabilidade (2005) pela Fundação Educacional de Caratinga - FUNEC. Diretora de Pesquisa, Extensão e EAD da FAVENI - Faculdade Venda Nova do Imigrante, e Professora Titular do Centro Universitário de Caratinga - UNEC.

${ }^{2}$ Arquiteto e Urbanista (2014) e Especialista em Gestão de Projetos e Obras: Orçamentos e Perícia (2017) pela Faculdade de Ciências Humanas - ESUDA. Especialista em Mobilidade Urbana e Transito (2017) pela Faculdade Venda Nova do Imigrante - FAVENI. ORCID: http://orcid.org/0000-0001-6431-447X E-mail: emanoel.s.amorim@gmail.com
} 
RODRIGUES, Ana Paula; AMORIM, Emanoel Silva de.

Turísticos Serrano y Agreste / Trairi (Río Grande del Norte). Además de citar las técnicas y las problemáticas que involucra la implantación de este tipo de infraestructuras en lugares históricos tomados por el IPHAN. El objetivo del trabajo es demostrar la importancia del conocimiento, basándose y justificando a través de argumentos la necesidad de la inversión en esa tipología de infraestructura, además de su agudeza en el proceso de preservación de los bienes culturales. Finalmente, se concluye que la eficiencia de esta infraestructura urbana puede contribuir también al aumento de la permanencia del turista en el lugar, y del gasto medio durante su estancia.

Palabras-clave: Mobilidad urbana; Patrimonio histórico; Señalización Turística; Infraestructura Urbana.

\section{INTRODUÇÃ̃O}

Atualmente, os sistemas de sinalização do trânsito foram se tornando mais complexo e onipresente, atendendo a demanda do usuário de se localizar e de fornecer o melhor acesso às atrações e recursos de um território.

Dentro deste cenário, surge a Sinalização de Orientação Turística, que conforme o EMBRATUR, DENATRAN e IPHAN (2001, p. 20) “é a comunicação efetuada por meio de um conjunto de placas de sinalização, implantadas sucessivamente ao logo de um trajeto estabelecido", com o objetivo de apresentar ao usuário os circuitos turísticos para alcançar os topônimos (atrativos turísticos).

A importância de sinalizar os topônimos vem da justificativa de empoderar a cultura local, a qual pode ser considerada como um diferencial que potencializa a competitividade de produtos e roteiros turísticos, além de reafirmar os valores e a identidade de um povo.

Dada esta tendência, torna-se imprescindível conhecer os critérios básicos, conceitos, argumentos, estratégias, metodologias, técnicas e problemáticas envolvendo a implantação da sinalização de orientação turística em sítios históricos, uma vez que eles são berços da cultura de um local.

\section{CONCEITOS LIGADOS À SINALIZAÇÃO TURÍSTICA}

\subsection{Sinalização Rodoviária}

Segundo o Manual de Sinalização Rodoviária (DNIT, 2010), a sinalização permanente é composta por placas, painéis, marcas no pavimento e elementos auxiliares constitui-se num sistema de dispositivos fixos de controle de tráfego que, por sua simples presença no ambiente operacional de uma via, regulam, advertem e orientam os seus usuários.

Por isso podemos idealizar que a sinalização rodoviária é um dos elementos fundamentais para o bom andamento do trânsito, orientado tanto motoristas quanto pedestres. 
RODRIGUES, Ana Paula; AMORIM, Emanoel Silva de. CONCEITOS, ARGUMENTOS, ESTRATÉGIAS, MÉTODOS, TÉCNICAS E PROBLEMÁTICAS ENVOLVENDO A IMPLANTAÇÃO (...). Revista Hospitalidade. São Paulo, volume 15, n.01, p. 180-197, jan-jun de 2018. Doi: https://doi.org/10.21714/2179-9164.2018v15n1.805

Para isso, a sinalização deve alcançar a confiança dos usuários, concedendo-lhes ainda um prazo para a tomadas de decisões. Esta autonomia é o resultado de diversos fatores, os quais compõem o ambiente operacional de uma via, como densidade e tipo do tráfego que se utiliza da via, velocidade dos veículos, complexidade de percurso e de manobra em função das características da via, tipo e intensidade de ocupação lateral da via (uso do solo).

O DNER (1998, p 01) afirma que "há uma dificuldade crescente em se atrair a atenção dos usuários para a sinalização permanente da via, o que requer projetos atualizados, o emprego de novas técnicas e materiais e correta manutenção".

Uma sinalização adequada é o produto de um processo de medidas que envolvam o "projeto", “implantação", “operação", "manutenção" e "materiais empregados”.

\subsection{Sinalização de Orientação Turística}

"A partir do momento em que o turista se afasta dos arredores de seu domicílio, começa a se deparar com situações que não lhe são habituais e que requerem atendimento específico" (EMBRATUR, DENATRAN, IPHAN, 2001, p. 14). Este fato ocorre devido à perda de marcos urbanístico, como paisagens, ruas, praças, edificações, equipamentos urbanos e elementos de sinalização aos quais está familiarizado em seus deslocamentos cotidianos.

Por esse motivo, a sinalização de orientação turística aplica-se aos usuários que não conhecem bem as regiões ou cidades onde estão circulando, especialmente ao serem visitadas pela primeira vez. Visando informar e orientar os usuários sobre a existência de atrativos turísticos, indicando os melhores percursos de acesso e distâncias a serem percorrida para se chegar ao local desejado.

A linguagem pictográfica, a cor padronizada internacionalmente e a articulação com a sinalização indicativa em geral são elementos que destacam as atrações turísticas e, ao mesmo tempo, tornam mais racional o caminho para cada uma delas, independentemente da nacionalidade e do idioma do turista.

O conjunto de atrativos de uma região ou cidade devem ter seus potenciais turísticos sistematizados através de um processo de hierarquização, garantido pelos valores agregados, sejam eles de natureza cultural, natural, lazer ou aventura, entre outros, e cuja seleção é motivada pelo estudo da oferta e da demanda turística desta localidade. 
RODRIGUES, Ana Paula; AMORIM, Emanoel Silva de. CONCEITOS, ARGUMENTOS, ESTRATÉGIAS, MÉTODOS, TÉCNICAS E PROBLEMÁTICAS ENVOLVENDO A IMPLANTAÇÃO (...). Revista Hospitalidade. São Paulo, volume 15, n.01, p. 180-197, jan-jun de 2018. Doi: https://doi.org/10.21714/2179-9164.2018v15n1.805

A sinalização de orientação turística é parte integrante do sistema viário devendo seguir objetivos e princípios que visa garantir a eficiência e a segurança para os usuários em vias urbanas e rurais.

\subsubsection{Objetivos e princípios da Sinalização de Orientação Turística}

Conforme o EMBRATUR, DENATRAN e IPHAN (2001, p. 16), para garantir a homogeneidade e eficácia da sinalização de orientação turística é preciso que seja concebida e implantada de forma a assegurar a aplicação dos seguintes objetivos e princípios básicos:

a) Legalidade: Cumprir o estabelecido no Código de Trânsito Brasileiro - CTB e nas Resoluções do Conselho Nacional de Trânsito - Contran.

b) Cumprir a legislação de preservação de sítios tombados pelo Instituto do Patrimônio Histórico e Artístico Nacional - Iphan e protegidos pela Lei de Arqueologia.

c) Padronização: Seguir um padrão preestabelecido quanto a: Formas e cores dos sinais; letras, tarjas, setas e pictogramas; aplicação - situações idênticas sinalizadas da mesma forma; colocação na via ou nas localidades.

d) Visibilidade, legibilidade e segurança: ${ }^{1}$ Ser visualizada e lida a uma distância que permita segurança e tempo hábil para a tomada de decisão, de forma a evitar hesitação e manobras bruscas. ${ }^{2}$ Selecionar trajetos de fácil compreensão para os usuários, com o objetivo de valorizar os aspectos de interesse cultural e turístico, levando em conta a segurança do trânsito. ${ }^{3}$ Garantir a integridade dos monumentos destacados e impedir que a sinalização interfira em sua visualização.

e) Resguardar as peculiaridades dos sítios.

f) Suficiência: 1 Oferecer as mensagens necessárias a fim de atender os deslocamentos dos usuários. ${ }^{2}$ Auxiliar a adaptação dos usuários às diversas situações viárias.

g) Continuidade e coerência: ${ }^{1}$ Assegurar a continuidade das mensagens até atingir o destino pretendido, mantendo coerência nas informações. ${ }^{2}$ Ordenar a cadência das mensagens, para garantir precisão e confiabilidade. 
RODRIGUES, Ana Paula; AMORIM, Emanoel Silva de. CONCEITOS, ARGUMENTOS, ESTRATÉGIAS, MÉTODOS, TÉCNICAS E PROBLEMÁTICAS ENVOLVENDO A IMPLANTAÇÃO (...). Revista Hospitalidade. São Paulo, volume 15, n.01, p. 180-197, jan-jun de 2018. Doi: https://doi.org/10.21714/2179-9164.2018v15n1.805

h) Atualidade e valorização: ${ }^{1}$ Acompanhar a dinâmica dos meios urbano e rural, adequando a sinalização a cada nova realidade. ${ }^{2}$ Assegurar a valorização da sinalização, mantendo-a atualizada e evitando gerar desinformações sucessivas.

i) Manutenção e conservação: ${ }^{1}$ Estar sempre conservada, limpa, bem fixada e, quando for o caso, corretamente iluminada.

\subsection{Acessibilidade Integrada}

De acordo com o Decreto Federal no 5.296/2004 em seu art.10, “a concepção e a implantação dos projetos arquitetônicos e urbanísticos devem atender aos princípios do Desenho Universal, tendo como referências básicas as normas técnicas da ABNT”.

Desenho Universal é a tradução do inglês Universal Design, portanto não se trata da representação de um desenho (drawing), mas sim de um desígnio ou concepção de projeto (design) com perspectivas universais.

O Desenho Universal não excluirá as ajudas técnicas para grupos específicos de pessoas com deficiência, quando necessárias (Convenção sobre os Direitos das Pessoas com Deficiência, art. $2^{\circ}$, ONU). Segundo Cambiaghi (2007, p. 20) o desenho universal é composto por sete princípios:

a) Uso equitativo: É a característica do ambiente ou elemento espacial que faz com que ele possa ser visualizado por diversas pessoas, independente de idade ou habilidade. Para ter o uso equitativo devese: propiciar o mesmo significado de uso para todos; eliminar uma possível segregação e estigmatização; promover o uso com privacidade, segurança e conforto, sem deixar de ser um ambiente atraente ao usuário.

b) Uso flexível: É a característica que faz com que o ambiente ou elemento espacial atenda a uma grande parte das preferências e habilidades das pessoas. Para tal devem-se oferecer diferentes maneiras de uso, possibilitar o uso para destros e canhotos, facilitar a precisão e destreza do usuário e possibilitar o uso de pessoas com diferentes tempos de reação a estímulos. 
RODRIGUES, Ana Paula; AMORIM, Emanoel Silva de. CONCEITOS, ARGUMENTOS, ESTRATÉGIAS, MÉTODOS, TÉCNICAS E PROBLEMÁTICAS ENVOLVENDO A IMPLANTAÇÃO (...). Revista Hospitalidade. São Paulo, volume 15, n.01, p. 180-197, jan-jun de 2018. Doi: https://doi.org/10.21714/2179-9164.2018v15n1.805

c) Uso simples e intuitivo: É a característica do ambiente ou elemento espacial que possibilita que seu uso seja de fácil compreensão, dispensando para tal, experiência, conhecimento, habilidades linguísticas ou grande nível de concentração por parte das pessoas.

d) Informação de fácil percepção: Essa característica do ambiente ou elemento espacial faz com que seja redundante e legível quanto a apresentações de informações vitais. Essas informações devem se apresentar nos modos - visuais e táteis - fazendo com que a legibilidade da informação seja maximizada.

e) Tolerância ao erro: É uma característica que possibilita que se minimizem os riscos e consequências adversas de ações acidentais ou não intencionais na utilização do ambiente ou elemento espacial. Para tal devem-se agrupar os elementos que apresentam risco, isolando-os ou eliminando-os e evitar ações inconscientes em tarefas que requeiram vigilância.

f) Esforço físico mínimo: Para ser usado eficientemente, com conforto e o mínimo de esforço e cansaço.

g) Dimensão e espaço para aproximação e uso: Essa característica diz que o ambiente ou elemento espacial deve ter dimensão e espaço apropriado para aproximação, alcance, manipulação e uso, independente de tamanho de corpo, postura e mobilidade do usuário. Desta forma, deve-se: implantar sinalização em elementos importantes e tornar confortavelmente alcançáveis todos os componentes para usuários sentados ou em pé.

O IPHAN, através do Manual de Sinalização do Patrimônio Mundial no Brasil, que apresenta referências para a produção de projetos de sinalização dos sítios do Patrimônio Mundial no Brasil, define a acessibilidade como um dos princípios a serem obedecidos:

As placas indicativas e de orientação de pedestres devem levar o público ao seu destino, valorizando os aspectos de interesse cultural e turístico. Servem para guiar o visitante por meio de um percurso não apenas curto, mas também atrativo e instrutivo. É recomendável que as placas de trânsito direcionem turistas motorizados aos locais adequados de estacionamento de veículos, favorecendo assim a visitação dos sítios a pé. Isso evita a presença de veículos estacionados em torno da área declarada patrimônio. É importante ainda respeitar as regras de acessibilidade às pessoas com deficiência, considerando nos projetos de sinalização a altura das peças, a facilidade 
RODRIGUES, Ana Paula; AMORIM, Emanoel Silva de. CONCEITOS, ARGUMENTOS, ESTRATÉGIAS, MÉTODOS, TÉCNICAS E PROBLEMÁTICAS ENVOLVENDO A IMPLANTAÇÃO (...). Revista Hospitalidade. São Paulo, volume 15, n.01, p. 180-197, jan-jun de 2018. Doi: https://doi.org/10.21714/2179-9164.2018v15n1.805

de acesso a elas e, sempre que possível, a leitura em braile para deficientes visuais. (IPHAN, 2013, p. 03)

Para obter a configuração de um ambiente acessível é necessário entender as especificidades de cada usuário, reconhecer as barreiras ou exigências de um ambiente e implantar melhorias para a diminuição da situação de incapacidade e, com isso, equiparar as oportunidades. A aplicação da acessibilidade e do desenho universal em ambientes públicos não está ligada somente a benfeitorias para portadores de necessidades especiais. A busca por permitir que todos os usuários desfrutem de um mesmo ambiente, em condições seguras, pode ser conceituada como Acessibilidade Integrada, que é a equiparação das oportunidades para todos os usuários, seja ele PDE (Portador de necessidades especiais) ou não. A partir desse entendimento, a indicação de melhorias abrange uma diversidade de usuários, entre eles: cegos ou com baixa visão, cadeirantes, turistas, anões, analfabetos, crianças, idosos e outros.

O CBT - Código Brasileiro de Transito atualmente não exige a tradução das informações, porém existem diversos PL - Projetos de Lei em tramitação que discutem a obrigatoriedade de que informações turísticas de responsabilidade de órgãos públicos serão expressas nos idiomas português, espanhol e inglês. A exemplo, PL 7.033/2014, do Senado Federal, que prever a alteração do Art. $80, \S 3^{\circ}$ do Código Brasileiro de Trânsito, assim "nos trechos que sejam de interesse turístico ou estejam próximos a fronteira com outros países, a sinalização vertical de indicação e a especial de advertência, quando não expressas exclusivamente por meio de pictograma, deverão conter legenda enunciada nos idiomas português, espanhol e inglês".

\section{ARGUMENTOS PARA A IMPLANTAÇÃO DA SINALIZAÇÃO TURÍSTICA EM SÍTIOS HISTÓRICOS}

Nos últimos anos, o Iphan vem evoluindo para uma concepção mais integrada de gerenciamento do patrimônio cultural brasileiro, ultrapassando as ações de identificação, restauração e conservação, com foco em monumentos e acervos isolados. É crescente o entendimento de que o patrimônio está intrinsecamente relacionado a temas globais como o desenvolvimento econômico e social (EMBRATUR, DENATRAN e IPHAN, 2001).

Neste sentido, uma forma eficaz de proporcionar transformações favoráveis para o setor é aumentar a quantidade de programas e investimentos, trabalhando em conjunto com o empresariado e da mobilização das comunidades turísticas. Entre esses programas e 
RODRIGUES, Ana Paula; AMORIM, Emanoel Silva de. CONCEITOS, ARGUMENTOS, ESTRATÉGIAS, MÉTODOS, TÉCNICAS E PROBLEMÁTICAS ENVOLVENDO A IMPLANTAÇÃO (...). Revista Hospitalidade. São Paulo, volume 15, n.01, p. 180-197, jan-jun de 2018. Doi: https://doi.org/10.21714/2179-9164.2018v15n1.805

investimentos, surge a sinalização turística como ferramenta à promoção do turismo e lazer nos sítios históricos.

Em complemento, abaixo estão listados um conjunto de argumentos que podem ser utilizados para a defesa da implantação da sinalização turística em sítios históricos.

\subsection{Argumentos socioculturais}

As cidades são espaços de encontros, de convivências, de história, cada qual com suas singularidades, fruto da ocupação e produção espacial, possuem atratividades diversas que motivam suas visitações, mas, para isso, devem ser locais adequados ao convívio em sociedade ao apresentarem qualidades sociais, culturais e ambientais que atendam às necessidades da população e estimulem a visitação. (ASCHER, 2010)

O turismo urbano permite rentabilizar social e economicamente investimentos, pois cada cidade é singular, oferece um espetáculo diferenciado, centraliza uma série de possibilidades que criam um grande poder de sedução [...] (CASTROGIOVANNI; GASTAL 1999, p. 6).

Nesse cenário, a sinalização torna-se uma ferramenta de empoderamento sociocultural, e quando adequadamente integrado ao planejamento do desenvolvimento turístico promove um processo dinâmico de socialização de um local.

Murta \& Goodey (1995) abordam a sinalização como uma das formas de interpretação do patrimônio, visando a sua valorização social e econômica. Os autores destacam que essa prática teve origem na Europa e Estados Unidos, em parte, devido ao crescente número de visitantes aos sítios históricos, que originou a necessidade educacional e econômica de democratizar o acesso e oferecer subsídios para a compreensão dos patrimônios.

Exposto as colocações acima, pode-se concluir que a sinalização é uma ferramenta de promoção a valorização sociocultural de um local, pois ela:

a) Fomenta que os visitantes, turistas ou não, conheçam o legado histórico do patrimônio da cidade; porque,

b) Valoriza a experiência dos visitantes, apresentando-lhes lugares organizados, com informações e preservados; e por fim,

c) Canaliza recursos para a preservação e promoção do patrimônio, através de investimentos do setor público ou do setor privado ou de parcerias entre 
RODRIGUES, Ana Paula; AMORIM, Emanoel Silva de. CONCEITOS, ARGUMENTOS, ESTRATÉGIAS, MÉTODOS, TÉCNICAS E PROBLEMÁTICAS ENVOLVENDO A IMPLANTAÇÃO (...). Revista Hospitalidade. São Paulo, volume 15, n.01, p. 180-197, jan-jun de 2018. Doi: https://doi.org/10.21714/2179-9164.2018v15n1.805

estes.

\subsection{Argumentos legais e técnicos}

Qualquer proposta de intervenção para implantação de sinalização de orientação turística em sítios históricos deverá ser desenvolvida segundo as diretrizes estabelecidas no Guia Brasileiro de Sinalização Turística da EMPETUR, IPHAN, DENATRAN (2001), Manual de Sinalização do Patrimônio Mundial no Brasil (2013), Comunicação e Cidades Patrimônio Mundial no Brasil (UNESCO, IPHAN, 2010) Manual de Sinalização Rodoviária do DNER (2010), Código de Transito Brasileiro (Lei 9503 de 23 de setembro de 1997), Manual Brasileiro de Sinalização de Transito, volume III - Sinalização Vertical de Indicação, verificando quando aplicáveis as Normas Brasileiras da ABNT pertinentes a projeto de sinalização.

\subsection{Argumentos econômicos}

"Acredita-se que o turismo é uma atividade que contempla a valorização de uma localidade e que gera renda e emprego, graças a seu efeito multiplicador nas economias locais". (SILVA \& MELO, 2012, p. 02)

Conforme o estudo anual "Viagens e Turismo: Impacto Econômico" - desenvolvido pelo Conselho Mundial de Viagens e Turismo (WTTC, na sigla em inglês), entidade que reúne os maiores empresários de turismo no mundo - o Brasil está em $6^{\circ}$ lugar no ranking de países que apresenta atividade econômica impactante. O estudo foi realizado em 184 países e leva em conta vários indicadores do setor, como: importância do turismo para o PIB (Produto Interno Bruto), geração de empregos, divisas geradas por turistas internacionais e investimentos públicos e privados.

Diante disso, Silva \& Melo (2012) conclui que, “a sinalização turística tem como finalidade garantir o acesso fácil às informações sobre quaisquer atrativos turísticos e por sua vez, possibilitar um deslocamento acessível”. Contudo, Pesquisas efetuadas com turistas estrangeiros revelam, porém, que a sinalização deficiente é uma das mais frequentes queixas daqueles que nos visitam. De fato, os viajantes estrangeiros ressentem-se da dificuldade de obter informações claras e precisas em placas de sinalização, materiais impressos, sonoros e visuais. (Projeto de Lei - PL 7.033/14, BRASIL, 2014) 
RODRIGUES, Ana Paula; AMORIM, Emanoel Silva de. CONCEITOS, ARGUMENTOS, ESTRATÉGIAS, MÉTODOS, TÉCNICAS E PROBLEMÁTICAS ENVOLVENDO A IMPLANTAÇÃO (...). Revista Hospitalidade. São Paulo, volume 15, n.01, p. 180-197, jan-jun de 2018. Doi: https://doi.org/10.21714/2179-9164.2018v15n1.805

\subsection{Argumentos sustentáveis}

Sintetizando os argumentos anteriores, temos a questão da sustentabilidade. Torna-se insustentável desconsiderar que a implantação da sinalização de orientação turística, pois ela supre as necessidades atuais da população, sem comprometer o futuro das próximas gerações. Ou seja, a sinalização de orientação turística está diretamente relacionada ao desenvolvimento econômico e material sem agredir o meio ambiente, usando os recursos de forma inteligente visando a preservação e conservação do patrimônio cultural em sítios históricos.

\section{ESTRATÉgias PARA A IMPLANTAÇÃO DA SINALIZAÇÃo DE ORIENTAÇÃO TURÍSTICA EM SÍTIOS HISTÓRICOS}

O desenvolvimento da sinalização de orientação turística faz parte do planejamento da cidade, em seu âmbito regional e urbano, envolvendo inclusive os aspectos mais específicos do local, o qual é fundamental para a definição da estratégia de sinalização turística.

“A estratégia de sinalização é basicamente a definição de como pedestres e usuários de veículos podem utilizar a infraestrutura local, para atingir os atrativos existentes por meio da escolha dos melhores trajetos" (EMBRATUR, DENATRAN e IPHAN, 2001, p. 25). Para isso, deve-se delimitar a área de abrangência da intervenção, assim como, o nível de conhecimento que a população tem sobre os atrativos turísticos deste perímetro, logo após é possível selecioná-los e hierarquizá-los.

Segundo EMBRATUR, DENATRAN e IPHAN (2001) a definição da estratégia de sinalização considera duas etapas básicas de desenvolvimento:

a) Diagnóstico da situação existente, englobando o levantamento e a análise das informações essenciais da região, do município e do local de intervenção, e diagnóstico da rede viária, para veículos e pedestres, e dos atrativos turísticos existentes.

b) Definição da lógica a ser adotada, a partir do conhecimento e da análise das condições existentes, fundamentadas na etapa anterior. $O$ esquema de sinalização de orientação deve contemplar a melhor forma para atender às necessidades de informações sobre a região, as cidades e os atrativos turísticos. Este esquema irá englobar os critérios para seleção do sistema viário de acesso 
RODRIGUES, Ana Paula; AMORIM, Emanoel Silva de.

ISSN 1807-975X

CONCEITOS, ARGUMENTOS, ESTRATÉGIAS, MÉTODOS, TÉCNICAS E PROBLEMÁTICAS ENVOLVENDO A IMPLANTAÇÃO (...). Revista Hospitalidade. São Paulo, volume 15, n.01, p. 180-197, jan-jun de 2018. Doi: https://doi.org/10.21714/2179-9164.2018v15n1.805

para veículos e pedestres, e critérios para seleção do sistema referencial turístico.

\section{METODOLOGIA PARA A IMPLANTAÇÃO DA SINALIZAÇÃO DE ORIENTAÇÃO TURÍSTICA EM SÍTIOS HISTÓRICOS}

O Guia Brasileiro de Sinalização Turística da EMPETUR, IPHAN, DENATRAN (2001) não cita um cronograma sistemático para elaboração do projeto de sinalização de orientação turística em sítios históricos, porém foi realizado alguns estudos de casos para traçar uma metodologia projetual. Em análise foi estudado os projetos de sinalização de orientação turística na ${ }^{1}$ Cidade de Olinda (Pernambuco), na ${ }^{2}$ Cidade do Recife (Pernambuco), nos ${ }^{3}$ Pólos Turísticos Serrano e Agreste/Trairi (Rio Grande do Norte), os quais seguiram as etapas citadas na Figura 1:

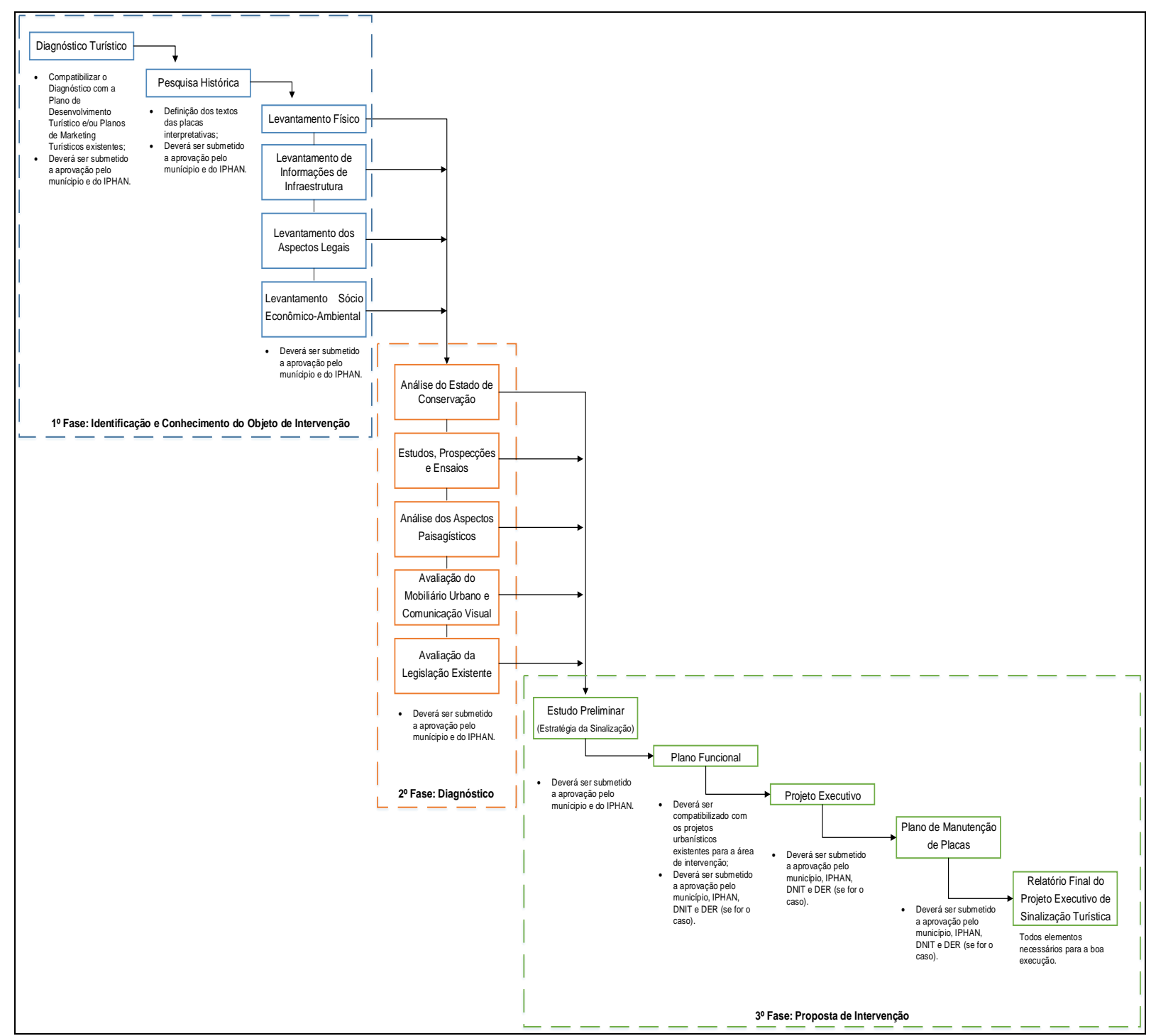

Figura 01: Organograma para elaboração de projetos de sinalização de orientação turísticas.

Fonte: Autor, 2017. 
RODRIGUES, Ana Paula; AMORIM, Emanoel Silva de. CONCEITOS, ARGUMENTOS, ESTRATÉGIAS, MÉTODOS, TÉCNICAS E PROBLEMÁTICAS ENVOLVENDO A IMPLANTAÇÃO (...). Revista Hospitalidade. São Paulo, volume 15, n.01, p. 180-197, jan-jun de 2018. Doi: https://doi.org/10.21714/2179-9164.2018v15n1.805

\section{1. $1^{\circ}$ Fase: Identificação e Conhecimento do Objeto de Intervenção}

Esta etapa foi responsável pela identificação e caracterização a área de projeto quanto aos aspectos relativos ao meio ambiente urbano, às disposições da legislação incidente na área, ao contexto histórico, socioeconômico e cultural e por fim, quanto a sua significação atual e ao longo do tempo. Foram atividades componentes desta etapa:
a) Diagnóstico turístico
b) Pesquisa Histórica
c) Levantamento Físico (características geométricas do espaço)
d) Levantamento de Informações de Infraestrutura
e) Levantamento dos Aspectos Legais
f) Levantamento Sócio Econômico-Ambiental

\section{2. $2^{\circ}$ Fase: Diagnóstico}

Esta fase, complementou a anterior no que diz respeito ao conhecimento do objeto, trata-se das análises das características do espaço público à luz de determinado enfoque/problema ou interesse. Os aspectos que devem ser considerados nesta etapa referem-se ao estado de conservação da área de projeto e equipamentos urbanos, condições de uso, apropriação pela comunidade, adequação ao conjunto e, fundamentalmente, interferências ambientais e visuais à perfeita fruição da ambiência do patrimônio cultural urbano. Destacamos como componentes desta etapa:
a) Análise do Estado de Conservação;
b) Estudos, Prospecções e Ensaios;
c) Análise dos Aspectos Paisagísticos;
d) Avaliação do Mobiliário Urbano e Comunicação Visual;
e) Avaliação da Legislação Existente.

\section{3. $3^{\circ}$ Fase: Proposta de Intervenção}

Compreendeu a definição do conjunto de ações necessárias para caracterizar a intervenção, determinando soluções, definindo usos e procedimentos de execução, abordados técnica e conceitualmente. Os quais foram desenvolvidos em cinco produtos:

a) Produto 1: Estudo Preliminar (Estratégia da Sinalização); 
RODRIGUES, Ana Paula; AMORIM, Emanoel Silva de. CONCEITOS, ARGUMENTOS, ESTRATÉGIAS, MÉTODOS, TÉCNICAS E PROBLEMÁTICAS ENVOLVENDO A IMPLANTAÇÃO (...). Revista Hospitalidade. São Paulo, volume 15, n.01, p. 180-197, jan-jun de 2018. Doi: https://doi.org/10.21714/2179-9164.2018v15n1.805

b) Produto 2: Plano Funcional;

c) Produto 3: Projeto Executivo

d) Produto 4: Plano de Manutenção de Placas

e) Produto 5: Relatório Final do Projeto Executivo de Sinalização Turística

\section{TÉCNICAS PARA A IMPLANTAÇÃO DA SINALIZAÇÃO TURÍSTICA EM SÍTIOS HISTÓRICOS}

Ao desenvolvimento da identidade visual da sinalização turística em sítios históricos deve levar em consideração diversos fatores, como: Modalidade de Acesso, Tipologias das Placas, Tipo de Fixação e Suportes, Dimensionamento e Tipologias dos Materiais e Especificações gerais. "Neste sentido, é fundamental que seja mantida a padronização em todos os planos desenvolvidos, independente de sua abrangência e do número de atrativos a serem sinalizados”. (EMBRATUR, DENATRAN e IPHAN, 2001, p. 25).

\subsection{Modalidade de acesso - Usuários de veículos motorizados}

Segundo a EMBRATUR, DENATRAN e IPHAN (2001), para deslocamentos e acessos feitos por meio de veículo motorizado, será escolhido um sistema viário com capacidade suficiente para a circulação e, ao mesmo tempo, compatível com as políticas de desenvolvimento e de organização territorial, especialmente quando os trajetos se encontram em áreas urbanas tombadas ou protegidas por alguma legislação.

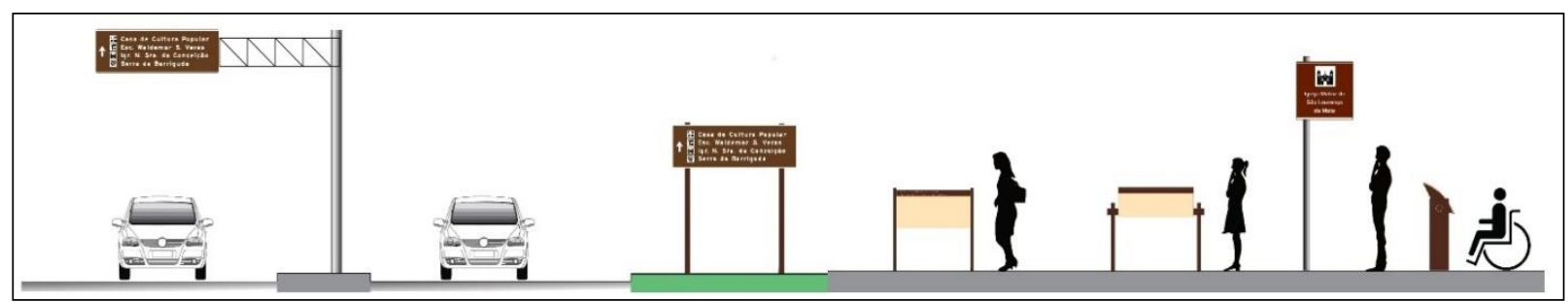

Figura 02: Componentes do sistema de sinalização turística em patrimônio histórico.

Fonte: Projeto de Sinalização Turística para os Polos Turísticos do Rio Grande do Norte, 2016. 


\section{HOSPITALIDADE}

ISSN 1807-975X
RODRIGUES, Ana Paula; AMORIM, Emanoel Silva de. CONCEITOS, ARGUMENTOS, ESTRATÉGIAS, MÉTODOS, TÉCNICAS E PROBLEMÁTICAS ENVOLVENDO A IMPLANTAÇÃO (...). Revista Hospitalidade. São Paulo, volume 15, n.01, p. 180-197, jan-jun de 2018. Doi: https://doi.org/10.21714/2179-9164.2018v15n1.805

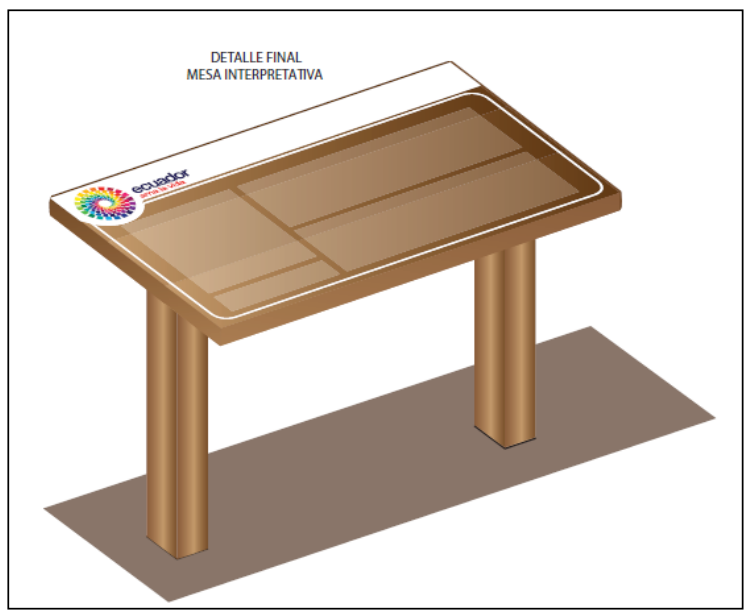

Figura 03: Placa Interpretativa em Madeira.

Fonte: Manual de Señalización Turística de Ecuador, 2011.

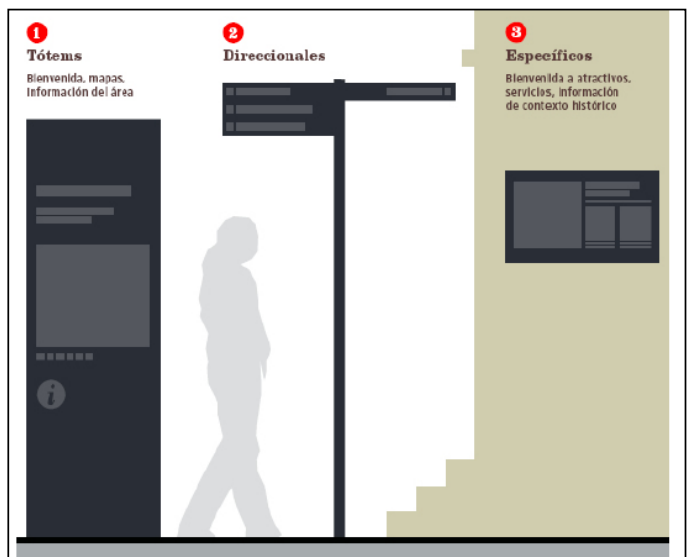

Figura 04: Componentes do sistema de sinalização turística de Pedestres.

Fonte: Plan de Señalización Turística Vial y Peatonal de Bogotá, 2010

\subsection{Modalidade de acesso - Usuários a pé}

Segundo a EMBRATUR, DENATRAN e IPHAN (2001), para os pedestres, a sinalização também deve promover os melhores percursos, integrando e conectando os atrativos turísticos entre si e às demais atividades, sendo, contudo, resultante de uma estratégia diferenciada e específica, que trabalhe sobre o Sistema Viário de Acesso e o Sistema Referencial Turístico, observando as necessidades, potencialidades e limitações próprias dos deslocamentos a pé. 
RODRIGUES, Ana Paula; AMORIM, Emanoel Silva de. CONCEITOS, ARGUMENTOS, ESTRATÉGIAS, MÉTODOS, TÉCNICAS E PROBLEMÁTICAS ENVOLVENDO A IMPLANTAÇÃO (...). Revista Hospitalidade. São Paulo, volume 15, n.01, p. 180-197, jan-jun de 2018. Doi: https://doi.org/10.21714/2179-9164.2018v15n1.805

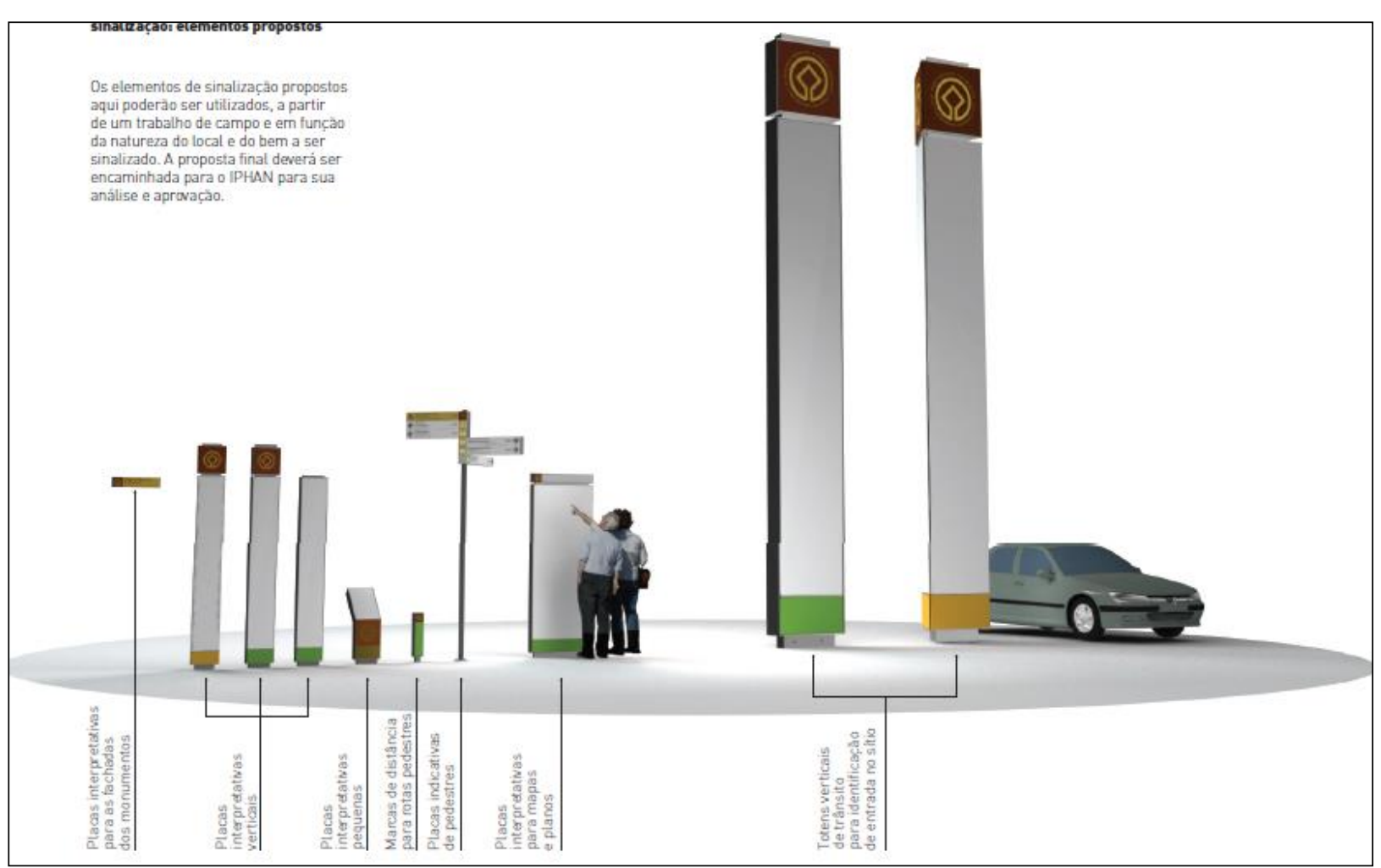

Figura 05: Componentes do sistema de sinalização turística em cidades patrimônio mundial. Fonte: IPHAN, 2013.

\section{PROBLEMÁTICAS ENVOLVENDO A IMPLANTAÇÃO DA SINALIZAÇÃO TURÍSTICA EM SÍTIOS HISTÓRICOS}

Segundo o Guia Brasileiro de Sinalização Turística da EMPETUR, IPHAN,

DENATRAN (2001), frequentemente são observados equívocos nos sistemas de sinalização de orientação turística. No Quadro 1 são citados alguns equívocos, as causas destes e as ações mitigadoras para sanar esses erros.

\begin{tabular}{|c|c|c|}
\hline Equívocos & Causas & Ações Mitigadoras ou Formas de Prevenção \\
\hline $\begin{array}{l}\text { Seleção de topônimos que não constituem um } \\
\text { sistema referencial abrangente e representativo, } \\
\text { deixando de proporcionar, por isso, o pleno } \\
\text { atendimento às necessidades de deslocamentos } \\
\text { dos usuários. Fonte: GBST (2001) }\end{array}$ & Erro projetual & \multirow{2}{*}{$\begin{array}{l}\text { Recomenda-se que ao desenvolver um Projeto } \\
\text { de Sinalização Turística tenha pelo } \\
\text { conhecimento do perímetro de intervenção, } \\
\text { para isso deve ser feito estudos com identificar } \\
\text { e conhecer a área, como também, e analisar, } \\
\text { avaliar e diagnosticar possíveis conflitos. } \\
\text { Somente com base nesses estudos } \\
\text { preliminares é que o projetista possuirá plena } \\
\text { capacidade de desenvolver uma proposta de }\end{array}$} \\
\hline $\begin{array}{l}\text { Falta de continuidade nas mensagens utilizadas, } \\
\text { com interrupção da informação, dificultando ao } \\
\text { usuário atingir seu destino. Fonte: GBST (2001) }\end{array}$ & Erro projetual & \\
\hline
\end{tabular}


RODRIGUES, Ana Paula; AMORIM, Emanoel Silva de. CONCEITOS, ARGUMENTOS, ESTRATÉGIAS, MÉTODOS, TÉCNICAS E PROBLEMÁTICAS ENVOLVENDO A IMPLANTAÇÃO (...). Revista Hospitalidade. São Paulo, volume 15, n.01, p. 180-197, jan-jun de 2018. Doi: https://doi.org/10.21714/2179-9164.2018v15n1.805

\begin{tabular}{|c|c|c|}
\hline Equívocos & Causas & Ações Mitigadoras ou Formas de Prevenção \\
\hline $\begin{array}{l}\text { Placas com diferentes critérios de diagramação, } \\
\text { nas mais variadas formas, sem padrão de } \\
\text { ordenação das informações e mensagens. Fonte: } \\
\text { GBST (2001) }\end{array}$ & Erro projetual & $\begin{array}{l}\text { intervenção respeitando os critérios } \\
\text { estabelecidos pelo GBST, assim como, todos } \\
\text { os normativos ligados ao assunto. }\end{array}$ \\
\hline $\begin{array}{l}\text { Trajetos selecionados inadequados aos } \\
\text { deslocamentos. Fonte: GBST (2001) }\end{array}$ & Erro projetual & \\
\hline $\begin{array}{l}\text { Placas instaladas em locais que comprometem a } \\
\text { visualização ou a segurança, além de trazer } \\
\text { conflito com o bem histórico. Fonte: GBST } \\
(2001)\end{array}$ & Erro projetual & \\
\hline $\begin{array}{l}\text { Placas confeccionadas em materiais inadequados. } \\
\text { Fonte: GBST (2001) }\end{array}$ & Erro projetual & \\
\hline $\begin{array}{l}\text { Utilização de formatos e tamanhos de letras e } \\
\text { algarismos que não proporcionam legibilidade. } \\
\text { Fonte: GBST (2001) }\end{array}$ & Erro projetual & $\begin{array}{l}\text { Recomenda-se que ao desenvolver um Projeto } \\
\text { de Sinalização Turística, o projetista deverá } \\
\text { seguir fielmente o GBST, assim como, todos } \\
\text { os normativos ligados ao assunto. }\end{array}$ \\
\hline Falta de manutenção. Fonte: Autor (2017) & $\begin{array}{l}\text { Gestão } \\
\text { Pública } \\
\text { Ineficiente }\end{array}$ & $\begin{array}{l}\text { Recomenda-se que todo o Projeto de } \\
\text { Sinalização Turística seja acompanhado com } \\
\text { um Plano de Manutenção, o qual irá descrever } \\
\text { a periodicidade das vistorias e os elementos a } \\
\text { serem analisados, como: visibilidade, limpeza } \\
\text { e danos. As ocorrências registradas serão parte } \\
\text { de relatórios que irá balizar as futuras tomadas } \\
\text { de decisões mitigadoras por parte da } \\
\text { Administração Pública. }\end{array}$ \\
\hline Vandalismo. Fonte: Autor (2017) & $\begin{array}{l}\text { Gestão } \\
\text { Pública } \\
\text { Ineficiente }\end{array}$ & $\begin{array}{l}\text { O desafio de combater o vandalismo deve ser } \\
\text { estudado profundamente pela administração } \\
\text { pública. Em tese não existem soluções únicas } \\
\text { ou especificas. Deverá haver um estudo } \\
\text { socioambiental sobre moradores, ações de } \\
\text { educação patrimonial e ambiental, assim } \\
\text { como, a parceria com os entes da segurança } \\
\text { pública. }\end{array}$ \\
\hline Erros de traduções. Fonte: Autor (2017) & Erro projetual & $\begin{array}{l}\text { Recomenda-se que na equipe multidisciplinar } \\
\text { de elaboração do projeto possua tradutores } \\
\text { juramentados, os quais são habilitados para } \\
\text { fazer traduções oficiais. }\end{array}$ \\
\hline
\end{tabular}

Quadro 01: Problemáticas envolvendo a implantação da sinalização turística em sítios históricos. Fonte: IPHAN (2013), adaptado pelo Autor, 2017.

\section{CONCLUSÕES}

A sinalização de Orientação Turística é um fator de grande importância para a satisfação do turista no destino, através de uma sinalização eficiente com orientações claras e precisas, o turista pode potencializar sua visitação no destino, e conhecer melhor o local. O 
RODRIGUES, Ana Paula; AMORIM, Emanoel Silva de.

CONCEITOS, ARGUMENTOS, ESTRATÉGIAS, MÉTODOS, TÉCNICAS E PROBLEMÁTICAS ENVOLVENDO A IMPLANTAÇÃO (...). Revista Hospitalidade. São Paulo, volume 15, n.01, p. 180-197, jan-jun de 2018. Doi: https://doi.org/10.21714/2179-9164.2018v15n1.805

turista que não tem como meta especifica a visitação, ou que tenha um objetivo de visitação muito restrito, pode ter a curiosidade despertada para determinados atrativos que estejam sinalizados em seu percurso. Dessa forma a eficiência desta infraestrutura urbana pode contribuir também para o aumento da permanência do turista no local, e do gasto médio durante sua estadia.

A preservação e, ao mesmo tempo, a compreensão dos sítios históricos são uma constante nos dias de hoje. O processo de preservação é extremamente complexo e, por que não dizer, difícil, tendo em vista que demanda recursos nem sempre disponíveis e, às vezes, vai de encontro a um processo de crescimento urbano nem sempre saudável.

Dentro do processo de preservação, a sinalização turística surge como um aliado importante para o entendimento dos sítios e monumentos, unindo informação e educação patrimonial. As Cartas Patrimoniais definem uma série de ações e sugestões para a preservação de sítios históricos e, embora não haja posicionamentos específicos acerca da sinalização nessas áreas, percebe-se que há critérios gerais de como intervir, e como a inserção de quaisquer novos elementos em sítios históricos é uma intervenção, deve-se dedicar atenção à sinalização turística.

\section{REFERÊNCIAS}

AMORIM, E. S.; BAPTISTA, A. H. N. Aplicação da Acessibilidade Integrada no Mapa das Linhas do METROREC. In: Congresso Nacional de Pesquisa e Ensino em Transporte ANPET XXVII, 2013, Belém/PA.

ASCHER, François. Os novos princípios do urbanismo. Trad. Nadia Somekh. São Paulo: Romano Guerra, 2010.

BRASIL. CÓDIGO DE TRÂNSITO BRASILEIRO. Código de Trânsito Brasileiro: instituído pela Lei no 9.503, 23 de outubro de 1997. 3. ed.- Brasília: DENATRAN, 2008.

BRASIL. DECRETO FEDERAL No 5.296/2004, de 2 de dezembro de 2004.

BRASIL. Departamento Nacional de Estradas de Rodagem. Diretoria de Desenvolvimento Tecnológico. Divisão de Capacitação Tecnológica. Manual de sinalização rodoviária. - 2 ed. - Rio de Janeiro, 1998.

BRASIL. Departamento Nacional de Infraestrutura de Transportes. Diretoria Executiva. Instituto de Pesquisas Rodoviárias. Manual de sinalização rodoviária. -3.ed. - Rio de Janeiro, 2010.

BRASIL. Embratur - Instituto Brasileiro de Turismo. Denatran - DEPARTAMENTO 
RODRIGUES, Ana Paula; AMORIM, Emanoel Silva de. CONCEITOS, ARGUMENTOS, ESTRATÉGIAS, MÉTODOS, TÉCNICAS E PROBLEMÁTICAS ENVOLVENDO A IMPLANTAÇÃO (...). Revista Hospitalidade. São Paulo, volume 15, n.01, p. 180-197, jan-jun de 2018. Doi: https://doi.org/10.21714/2179-9164.2018v15n1.805

NACIONAL DE TRÂNSITO. IPHAN - Instituto do Patrimônio Histórico e Artístico Nacional. Guia Brasileiro de Sinalização Turística. - 1 ed. - Rio de Janeiro, 2001.

BRASIL. Instituto do Patrimônio Histórico e Artístico Nacional. Sinalização do Patrimônio Mundial no Brasil: orientações técnicas para aplicação / Instituto do Patrimônio Histórico e Artístico Nacional. Brasília : IPHAN, 2013. 44 p., il.

BRASIL. PROJETO DE LEI No 7.033-A, de 2014, do Senado Federal.

CAMBIAGHI, S. Desenho Universal. Métodos e Técnicas para Arquitetos e Urbanistas. São Paulo: Senac, 2007.

CASTROGIOVAnNi, Antonio Carlos. Turismo e ordenação no espaço urbano. In: YAZIGI, Eduardo (org.). Turismo urbano. São Paulo: Contexto, 2001.

DIRETORIA DE DESENVOLVIMENTO TECNOLÓGICO. Divisão de Capacitação Tecnológica. Manual de sinalização rodoviária. - 2 ed. - Rio de Janeiro, 1998.

ECADOR. Ministerio de Turismo. Manual de Señalización Turística. Quito, 2011.

INSTITUTO DISTRITAL DE TURISMO - IDT. Plan de señalización turística vial y peatonal de Bogotá. Bogotá: IDT, 2010.

MURTA, S. M.; GOODEY, B. Interpretação do patrimônio para o turismo sustentado: um guia. Belo Horizonte MG: SEBRAE, 1995.

SECRETARIA DE TURISMO DO ESTADO DE PERNAMBUCO - SETUR. Projeto de Sinalização Turística nas Cidades de Recife e Olinda. Recife: SETUR-PE . 2013.

SECRETARIA DE TURISMO DO ESTADO DO RIO GRANDE DO NORTE - SETUR. Projeto Executivo de Sinalização Turística para os Polos Turísticos do Rio Grande do Norte - Serrano e Agreste/Trairi. Natal: SETUR-RN, 2014.

SILVA, F. \& Melo, R. Contribuição da sinalização turística para o desenvolvimento turístico da cidade de Parnaíba (PI, Brasil). Revista Brasileira de Pesquisa em Turismo. São Paulo, 6 (2), pp. 3 - 20, mai./ago. 2012

SOUZA, M. Sinalização turística e percepção do espaço geográfico. Turismo - Visão e Ação. Itajaí, 8(1), 165-176, 2006.

Artigo recebido em: 24/01/2018

Avaliado em: 27/03/2018

Aprovado em: 30/08/2018 